\title{
Consultor Jurídico do D.A.S.P.
}

A prestação de serviços eventuais, mediante recibo, não caracteriza relação de emprêgo, como se infere, a contrário sensu, do disposto no art. $3^{\circ}$ da Constituição das Leis do Trabalho.

- Ainda que houvesse vinculo empregaticio, rompera-se êste com a extinção da emprêsa, o que sòmente permitiria o recebimento da indenização, se devida.

- Cessando as atividades do jornal “A Manhã" em 1953, os seus empregados, ou foram transferidos para outra emprêsa incorporada ao patrimônio nacional (artigo 469. § $2 .^{\circ}$, da Consolidação das Leis do Trabalho), ou perderam qualquer relação de emprêgo com o jornal extinto, ainda que estivessem licenciados.

- Inaplicabilidade a êste últimos da faculdade conferida pelo $\S 7 .^{\circ}$ do art. 6..$^{\circ}$ da Lei n. 2.193 , de 1954 .

\section{PARECER}

\section{I}

Do despacho do Sr. Diretor-Geral dêste Departamento, que denegou pedido de transferência para o serviço público federal de quer: se intitulava ex-empregado da emprêsa "A Manhã", incorporada ao patrimônio nacional. recorre o interessado ao Exmo. Sr. Presidente da República.

2. Não há provas no processo de que o recorrente tenha sido, efetivamente, empregado aaquele jornal, pois que não se juntou ato $d$ ? admissão, embora conste, de certidão anexada por fotocópia, que percebeu, mediante recibos avulsos, remuneração por serviços eventuais prestados. Ao contrário, claramente se declara que o peticionário jamais foi registrado como empregado da emprêsa.

2. A Divisão do Pessoal dêste Departamento opina pela manutenção de ato recorrids. Nada obstante, deseja ouvir-me a respeito.

\section{II}

4. Os documentos juntos ao processo em nada auxiliam a pretensão do recorrente; antes, servem apenas para justificar a decisão de que interpôs recurso.

5. Seria, na verdade, bem fácil ao postulante comprovar a sua relação de emprêgo com o jornal "A Manhâ", se existente, bastando exibit o ato que o admitiu ao serviço da emprêsa, o'que, entretanto, deixou de fazer.

6. O que existe, a respeito de sua situação perante aquela emprêsa, é a declaração peremptória, constante do documento anexado por fotocópia pelo próprio recorrente, de que não foi dispensado, nem recebeu aviso prévio ou indenização, pelo fato de jamais ter sido registrado como empregado do jornal.

7. Ora, serviços eventuais prestados não caracterizam a relação de emprêgo, como se verifica, a contrário sensu, do preceituado no art. $3^{\circ}$ (caput) da Consolidação das Leis do Trabalho, assim redigido:

"Considera-se empregado tôda pessos fisica que prestar serviços de natureza nấ eventual a empregador, sob a dependência dêste e mediante salário» (grifei).

8. Ademais, encerrando-se as atividades da emprêsa «A Manhã» em junho de 1953, cessara qualquer vinculo porventura existente entre o jornal e o interessado, que não foi transferido para outra emprêsa jornalistica incorporada ao patrimônio nacional, a exemplo do que ocorreu com alguns empregados daquele matutino. Destarte, não poderia invocar o disposto no artigo $6 .^{\circ}$ - $7 .^{\circ}$, da Lei n. 2.193 , de 9 de março de 1954, que, quando entrou em vigor, já de há muito deixara de existir como emprêsa o jornal "A Manhã". 
9. Assim, ainda que houvesse o alegado vincula empregaticio, êste se teria desfeito com a extinção da emprêsa sem a transferência para outra incorporada ao patrimônio nacional, ainc.a que se lhe não tivesse dado aviso prévio, nem pago a indenização que fôsse devida. A rescisão do contrato de trabalho se teria operado, embora não se houvesse atendido ao direito do empregado, o que somente lhe possibilitaria reclamar reparação do ato dentro em dois anos da data daquela extinção, o que já se acha prescrito (art. 11 da Consolidação das Leis do Trabalho).

10. É irrelevante, por outro lado, a circunstância alegada pelo recorrente de que se encontrava licenciado sem vencimentos, pois, com a ruptura de vinculo de emprêgo, também se extinguira a licença.

11. Sou, pois, em conseqüência, pelo não provimento do recurso.

$\mathrm{E}^{\prime}$ ○ meu parecer. S.M.J.

Rio de Janeiro, 24 de março de 1959. Clenício da Silva Duarte, Consultor Juridicc.

\section{Aposentadoria com fundamen-} to no art. 197 , alinea a, do Decreto-lei $n^{\circ} 1.713$, de 1939.

- Não se tendo o interessado valido, em tempo hábil, do disposto na Lei $n^{\circ} 171$, de 1947, calutucou do direito à reversão com apoio naquele diploma legal.

- Nem há que invocar revisão de processo administrativo, ná forma do art. 233 do vigente Estatuto dos Funcionários, do momento em que a aposentadoria como penalidade não resultou do processo. que, aliás, fôra instaurado para apurar abandono de cargo, não tendo havido decisão, eis que fistra o processo sobrestado ent seit andamento.

\section{PARECER}

\section{I}

A hipótese é de pedido de revisão de processo administrativo, com invocação do artigo 233 do vigente Estatuto dos Funcionários (Lei $n^{\circ} 1.711$, de 28 de outubro de 1952).
2. Trata-sé de funcionário aposentado com fundamento no art. 197, alinea a, do antigo Estatuto dos Funcionários (Decreto-lei número 1.713 , de 28 de outubro de 1939), que dispunha:

«Art. 197. Fora dos casos previstos no artigo anterior, poderão ser aposentados independentemente de inspeção de saúde:

a) os funcionários cujo afastamento se impuser, a juizo exclusivo do Presidente da República, no interêsse do serviço público ou por conveniência do regime».

3. Embora tenha a Lei n. ${ }^{\circ} 171$, de 15 de dezembro de 1947 , permitido a reversão à atividade de todos os funcionários atingidos pelo dispositivo supratranscrito, condicionando o ato tão-sòmente a requerimento do interessado, dentro em noventa dias da promulgação da lei $\left(\right.$ art. $\left.1 .^{\circ}\right)$, não se valeu o suplicante dêsse direito, incorrendo, em consequiência, em caducidade.

4. Pretende, agora, valer-se do disposto no art. 233 do atual diploma básico dos servidores públicos, sob a alegação de que 0 ato se revestira de caráter punitivo e se alicerçara em processo administrativo então instaurado.

5. A D.P. e o D.A. do Ministério da Viação e Obras Públicas manifestaram-se contràriamente ao pedido de revisão, sob o fundamento de que a aposentadoria não foi decorrente do processo administrativo instaurado.

6. No mesmo sentido é a opinião da D.P. dêste Departamento, que, após minucioso histó-ico, concluiu por solicitar minha audiência sôbre o assunto.

\section{II}

7. Preceitua o art. 233 (caput) do Estatuto dos Funcionários em vigor:

«A qualquer tempo poderá ser requerida a revisão do processo administrativo de que resultou pena disciplinar, quando se aduzam fatos ou circunstâncias suscetiveis de justificar a inozência do requerente».

8. A revisão que se assegura é, por conseguinte, «do processo administrativo de que resultou pena disciplinar». Ora, não sendo a aposentadoria do requerente decretada em face das conclusões do processo administrativo, que, como o próprio interessado esclarece, fôra instaurado para apurar abandono de cargo, havendo sido tal processo, na expresssão do suplicante, cancelado (fls. 189), não há falar em revisão.

9. A matéria estava abrangida pelas disposições da Lei $n .^{\circ} 171$, de 1947 , que fixava 
prazo de caducidade para o requerimento de reversão, independentemente de qualquer formalidade de mérito, iniciativa que não tomou 0 interessado.

10. Não sendo caso de revisão de processo administrativo, eis que êste fôra sobrestado em seu andamento, sem que sẹ houvessem apurado os fatos que determinaram a sua instauração, a aposentadoria imposta com apoio no art. 197, alínea $a$, do Decreto-lei n. ${ }^{0} 1.713$, de 1939 , só poderia ser reconsiderada em face da Lei número 171 , de 1947, no prazo ali estatuido. Caducando êste, ficou definitivamente trancada qualquer revisão do ato.

11. A aposentadoria como penalidade, com assento no art. 197, alinea a, do Decreto-lei n. ${ }^{\circ} 1.713$, de 1939 , era ato de arbitrio, para cuja reparação houve lei especial. Se não se valeu dela o suplicante, na ocasião oportuna, não pode vir, agora, pleitear a revisão do ato com invocação do art. 233 do Estatuto dos Funcionários em vigor, que pressupõe a existência de um processo administrativo cujas conclusões importaram na aplicação de pena disciplinar, o que, como já suficientemente esclarecido, não é a hipótese.

12. A única via que resta ao interessado é a reversão nos têrmos do art. 68 do Estatuto dos Funcionários vigente, se o seu estado de saúde o permitir, o que, entretanto, não parece ser o caso, segundo se informa no processo.

13. Sou, em conseqüênc:a, pelo indeferimento do pedido do suplicante.

É o meu parecer. S.M.J.

Rio de Janeiro, 27 de dezembro de 1958. Clenício da Silva Duarte, Consultor Juridico.

Autorização de pesquisa de minérios. Cessão de metade dos direitos de pesquisa e de lavra.

- Impugnação do interessado, mediante recurso ao Presidente da República. Improcedência.

\section{PARECER}

\section{I}

Em recurso dirigido ao Exmo. Sr. Presidente da República, pretende-se a caducidade ou anulação de decretos que autorizaram o cidadão brasileiro Hermelino LOPES RODRI-
GUES FERREIRA a pesquisar minérios de ferro, manganês e associados na Serra do Yacadigo, Municipio de Corumbá, Estado de Mato Grosso.

2. Alega-se para tanto, em resumo, que a aprovação do relatório de pesquisa foi posterior ao prazo dos decretos de renovaçã́o $e$ que o concessionário cedeu metade dos scus direitos de pesquisa e de lavra pela escritura de 29 de dezembro de 1956, lavrada no $7^{\circ}$ Oficio de Notas desta Capital, no Livro 957, a fls. 35 verso, antes da aprovação do relatório, com o que teria infringido o disposto nos arts. 16, n. ${ }^{\circ}$ I, e 32 do Código de Minas (De. creto-lei n. 1.985, de 29 de janeiro de 1940).

3. Com a declaração de caducidade ou nulidade dos titulos, deseja o recorrente the seja autorizada a pesquisa pará as mesmas áreas indicadas naqueles decretos.

4. O assunto foi examinado, em várias oportunidades, pelo Ministério da Agricultura, concluindo êste sempre pela improcedência da pretensão do recorrente. Por determinação do Exmo. Sr. Presidente da Re pública, veio o processo a êste Departamento, sendo-me presente em conseqüência.

\section{II}

5. Quanto à primeira impugnação, está becn esclarecido no processo que o rclató. rio de que trata o art. $16, \mathrm{n}$. IX, do Código de Minas, embora efetivamente aprovado, como se argúi, após o prazo de renovação, sua apresentação, entretanto, ocorreu antes de escoar-se aquêle lapso de tempo. E o que a lei exige é a apresentação, e não a apro. vaçáo, dentro do referido prazo. Veja-se a redação desenganada de supra-referido artigo 16 , n. IX:

"Na conclusão dos trabalhos, dentro d", prazo da autorização, e sem prejuizo de quaisquer informaçõcs pedidas pelo D.N. P.M. no curso dêles, o concessionário apresentará um relatório circunstanciado sob a responsabilidade de profissional legalmente habilitado ao exercicio de engetharia de minas, com dados inform:tivos que habilitem o Govêrno a formar juizo seguro sôbre a reserva mineral da jazida, qualidade do minério e possibilidade de lavra..." (grifei).

6. Por ai se verifica que nâo procede a argüição de caducidade da autorização, por infringência do disposto no art. 16 , n. IX, do Código de Minas, plenamente atendido pelo concessionário. 
III

7. No que concerne à segunda objeção, também não tem razão o recorrente, como se verá a seguir.

8. Dispõe o art. $16, \mathrm{n}$. I, do mencionado Código:

"Art. 16. A autorização de pesquilsa, que terá por título um decreto, transcrito no livro próprio do D.N.P.M., será conferida nas seguintes condições:

I - O título será pessoal e sòmente transmissivel nos casos de herdeiros necessários ou de cônjuge sobrevivente, bem como no de sucessão comercial, desde que o sucessor satisfaça os requisitos dos números II e III do art. 14".

9. Não padece dúvida, do fato, que a autorização de pesquisa é um titulo inegociável, enquanto não aprovado o relatório, a partir de quando, e só então, perde essa caracteristica de inalienabilidade, como se vê do art. 20 do Código de Minas, cuja redação é a seguinte:

"O pesquisador, uma vez aprovado o relatório, terá um ano para requerer a um ano para requerer a autorização de lavra e dentro dêsse prazo poderá negociat o seu direito a essa autorização, na forma dêste Código" (grifei).

10. $E^{\prime}$ certo que a escritura de cessão de metade dos direitos de pesquisa e lavra dessas áreas, outorgada a terceiros pelo con. cessionário da autorização, tem a data de 29 de dezembro de 1956 e a aprovação do relatório só ocorreu em 30 de janeiro de 1957 , tendo sido publicada no Diário Oficial de 7 de fevereiro do mesmo ano (fls. 192 verso). Mas o fato está suficientemente esclarecido no processo, onde se verifica que houve equivoco do concessionário da autorização, sem a ocorrência de má-fé, tanto que, no dia imediato à publicação do despacho que aprovava - relatório, compareciam os interessados ao mesmo Ofício de Notas, lavrando a escritura de re-ratificação de fls. 188 e seguintes.

11. Ora, só seria anulável o ato, na espécie, se houvesse dolo ou fraude, nos têrmos do art. 147, n. II, do Código Civil, fatos êsses que se não presumem, não havendo o recorrente logrado comprová-los.

12. Também não houve o menor alcance ao disposto no art. 32 do Código de Minas, poís o que veda êsse preceito legal é a divisão da área de autorizaçăo, não tendo ĉsse efeito a escritura de cessão de metade dos direitos de pesquisa e lavra, que apenas significa $D$ condominio nesses direitos, eis que nessa es. critura não se delimita uma parte da área para o cedente e outra para os cessionários, mas o condominio de ambos sôbre tôda a área.

13. Estou, pois, de inteiro acôrdo com os brilhantes pareceres dos Drs. Olgmar Pedro RANGel, Assistente Turidico do Ministério da Agricultura (fls. 175 usque 178), e BENJAMIN DE CAMPOS, Consultor Juridico do mesmo Ministério (fls. 197 usque 200). Assim, também não se me afigura o recurso merecedor de provimento.

E' o meu parecer. S. M. J.

Rio de Janeiro, em 7 de abril de 1959. Cienício da Silva Duarte, Consultor Juridico. 